\title{
The influence of basin on earthquake responses of near-fault structure cluster due to the rupture of thrust fault
}

\author{
W. ZHONG \\ Chongqing College of Electronic Engineering, Chongqing, P. R. China
}

\begin{abstract}
KEYWORD: Basin; Earthquake response; Structure cluster; Near-fault; Investigated lump ABSTRACT: In order to study the influence of basin on seismic responses of near-fault structure cluster due to the rupture of thrust fault, an integrated simulation method is used and two different models of earth media without basin and with basin are established. The seismic responses of nearfault structure cluster are simulated during a hypothetical $M_{\mathrm{w}} 6.0$ earthquake. The presence of basin can increase greatly the bending moments of plane frame structures in structure cluster at the surface of the basin and variation range of horizontal displacement. There exists the trend of beating for both cases without basin and with basin by observing snapshots of simulated displacement of structure cluster. When simulating seismic responses of near-fault structure cluster, the geological structure of basin should be considered.
\end{abstract}

\section{INTRODUCTION}

Many studies showed that the existence of basin has great influence on ground motion in urban area, and then the subsurface geology of basin needs to be known in detail to simulate ground motions (Pitarka \& Irikura 1996, Morales et al. 1996, Graves et al. 1998, Graves \& Wald 2004, Graves 2008, Day et al. 2008). The basin regions that they studied are San Fernando basin, the Los Angeles basin, Granada basin and San Bernardino basin, where a number of building clusters in urban area are situated. Their research works have neglected the existence of structures in the cities on the surface of earth media and can not obtain the earthquake response of structures.

In fact, the earthquake response of structures is one of important reasons for the seismic hazard in city. Thus, the reasonable computational model should include structure clusters in city apart from earth media and seismic sources.

According to fault distance of the place where cities are situated, the cities can be classified into far-field cities and near-fault cities. In order to consider the existence of far-field building clusters in the cities on the basin, the three different types of building models were used to study site-city interaction (SCI) or earthquake responses of buildings by using incident plane wave (including plane $\mathrm{P}$ wave, plane SV wave and plane SH wave). Some researchers (Wirgin \& Bard 1996, Tsogka \& Wirgin 2003a, b, Groby et al. 2005, Groby \& Wirgin 2008, Semblat et al. 2002, Semblat et al. 2004, Kham et al. 2006, Semblat et al. 2008) simplified the buildings as blocks, some (Guéguen et al. 2000, Guéguen 2002, Boutin \& Roussillon 2004, Boutin \& Roussillon 2006, Uenishi 2010, Uenishi 2013) used oscillator models of buildings, still others (Lombaert \& Clouteau 2006, Lombaert \& Clouteau 2009) combined FEM models of frame structures with earth media.

In addition to the far-field cities on the basin as mentioned above, there are also many other nearfault cities on the basin during an earthquake. For the near-fault cities, because the characteristics of near-fault ground motions such as hanging-wall effect, directivity effect, near-fault velocity pulses, and static offsets can result in complicated seismic responses and severe earthquake disaster of nearfault superstructures in city, the rupture process of causative fault should be considered.

For the past few years, a few researchers used finite-fault seismic sources and building clusters in city situated on the basin to study the near-fault site-city interaction during a earthquake. Guidotti et al. (2012) studied the site-city interaction during the 22 February $2011 M_{\mathrm{W}} 6.2$ Christchurch earthquake. The concerned region is Christchurch Central Business District, which is situated on the surface of the alluvial basin and is composed of around 150 buildings. The research results showed that the presence of the city changes considerably ground motions inside the city of Christchurch. Isbili- 
roglu et al. (2015) studied coupled soil-structure interaction effects of building clusters during earthquakes. They simulated the coupled responses of multiple simplified building models located within the San Fernando Valley during the 1994 Northridge earthquake. In the research works mentioned above, a building or a set of buildings on urban area is simplified as a low-velocity block and then is connected to substratum. All blocks and half-space medium underneath the free surface constitute heterogeneous continuum. This type of block model of building is first proposed by Wirgin \& Bard (1996). However, this kind of simplified building model can not be used to obtain the actual earthquake responses of structures in civil engineering, e.g. the internal forces (bending moments, shear forces and axial forces of structural members) and the deformations of structure as well as the structural members.

In our previous work, Liu \& Zhong (2014) introduced an integrated system consisting of frame structure clusters, half-space viscoelastic earth medium and causative fault. Based on this integrated system, we developed an integrated numerical simulation method for flexural wave propagation in the plane frame structure and viscoelastic wave propagation in earth medium as well as bidirectional wave propagation between the plane frame structure and earth medium during a near-fault earthquake.

In this article, I shall use the integrated numerical simulation method in the literature (Liu \& Zhong 2014) and construct two different earth media models, which are respectively the cases without basin and with basin, to simulate seismic responses of frames in structure clusters at the surface of two earth media models during a hypothetical $M_{\mathrm{w}} 6.0$ earthquake induced by the rupture of thrust fault. And then I shall study the influence of basin on the bending moments of structures in cluster, snapshots of displacement of all structures and the displacement orbits of points on the roof in structures.

\section{THE INVESTIGATED LUMP METHOD FOR WAVE PROPAGATION IN THE INTEGRATED SYSTEM}

After rupture of causative fault, seismic waves propagate from the fault to the foundations of frame structure clusters, there will exist the following phenomena:

(1) wave propagation from the foundations into the structures,

(2) the scattering of waves from the foundations to earth medium,

(3) the radiation of energy from the structures due to structural vibration resulting from wave propagation in the structures.

In this article, plane frame structure clusters, half-space viscoelastic earth medium and causative fault constitute the integrated system as sketched in Figure 1(a). In order to achieve integrated simulation for seismic wave propagation in near-fault frame structure clusters and viscoelastic earth medium due to rupture of the causative fault, we have constructed three types of the investigated lumps (Liu et al. 2012, Liu \& Zhong 2014, Zhong \& Liu 2016): 1) the investigated lump in plane frame structure, 2) the investigated lump in viscoelastic earth medium and 3) the investigated lump for structure-soil connection. The schematic illustrations about these three types of investigated lumps in integrated simulation for wave propagation are respectively shaded parts A1, A2 and A3 shown in Figures. 2(b), (c). 


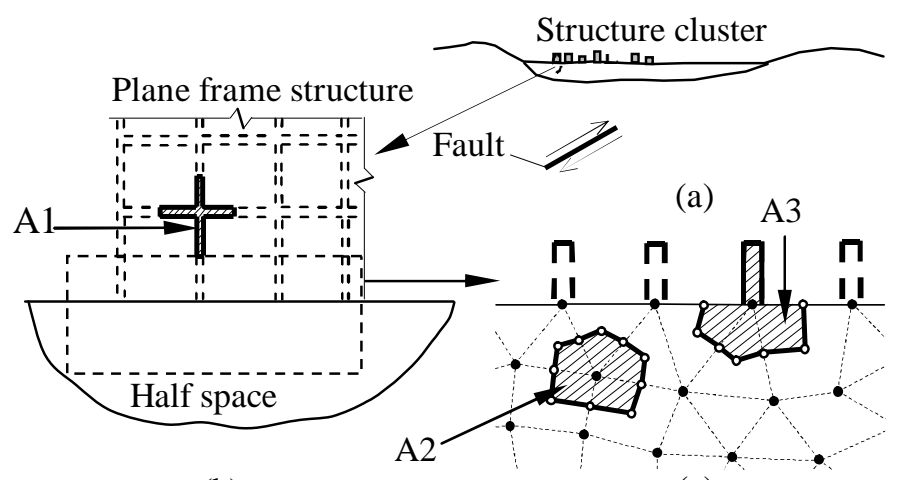

(b)

(c)

Figure 1. Schematic illustration of the investigated lumps in the integrated system. (a) Simplified diagram of the integrated system including structure cluster, half-space earth medium and fault. (b) The investigated lump (shaded part A1) in the plane frame structure in structure cluster shown in figure 1(a). (c) The investigated lump (shaded part A2) in earth medium and the investigated lump (shaded part A3) for structure-soil connection.

In our previous work, Liu \& Zhong (2014) have established governing equations of the above three types of the investigated lumps and given algorithm implementation of integrated numerical simulation method, which can achieve simultaneously flexural wave propagation in plane frame structure and viscoelastic wave propagation in earth medium as well as bidirectional wave propagation between the plane frame structure and earth medium during an near-fault earthquake. The key of implementation of the integrated method is the connection between structures and earth medium.

It is simple for program implementation of this integrated numerical simulation method. On the one hand, the structures model and half-space earth media are built independently. On the other, the method will be implemented by only telling the computer which investigated lumps in ground floor columns of frame structures and at the surface of half-space earth medium belong to the same investigated lump for structure-soil connection.

In this article, I shall use the integrated simulation method to obtain seismic responses of structure cluster due to the rupture of causative fault and study the influences of basin on earthquake responses of plane frame structures in structure cluster.

\section{NUMERICAL SIMULATION}

In this section, in order to study the influence of basin on the earthquake responses of structure cluster, two different models of earth media will be built for a hypothetical earthquake of $M_{\mathrm{w}} 6.0$. I will obtain the seismic responses of near-fault structure cluster on hanging wall during a hypothetical earthquake of $M_{\mathrm{w}} 6.0$ by using the integrated simulation algorithm. The bending moments of structure cluster, snapshots of simulated displacement of all structures in cluster S1 and the displacement orbits of points on the roof in structures b1 and b5 are given for the cases without basin and with basin during a thrust fault earthquake.

\section{Computational model}

The computational model include three parts: seismic source, earth media and frame structure cluster.

For the seismic source, finite-fault earthquake model used here is the same as the literature (Liu \& Zhong 2014). For a hypothetical earthquake of $M_{\mathrm{w}} 6.0$, the optimal size of each subfault is about 2.5 $\mathrm{km}$ and then the number of subfaults along the dip-slip direction is 3 . The average rise time and the final slip displacement for each subfault are respectively $2.0 \mathrm{~s}$ and $0.35 \mathrm{~m}$. The top edge of fault plane under the earth's surface and dip angle are set about $11.0 \mathrm{~km}$ and $48^{\circ}$, respectively. 


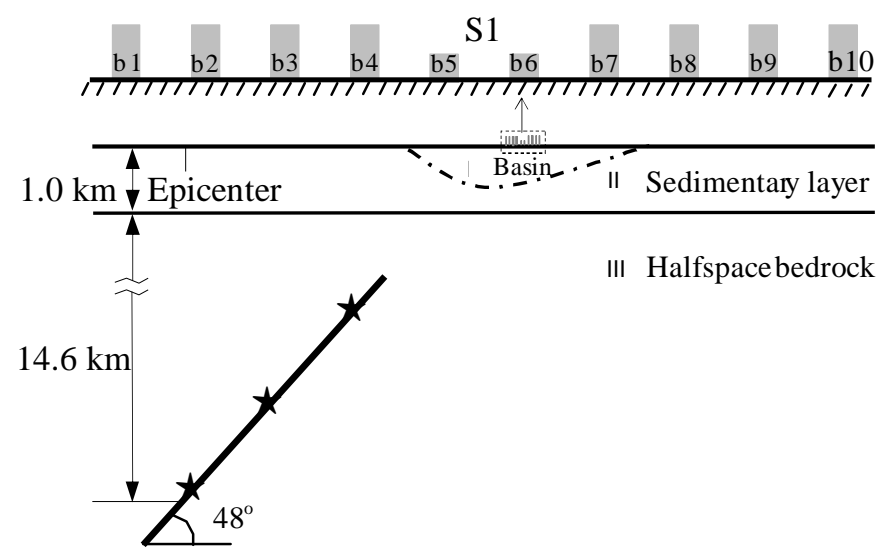

Figure 2. Computational model of the integrated system. The three dark stars denote three subfaults. The dash dot line is the interface between basin and sedimentary layer in "model 1". The "model 1" of earth media considers this interface and basin. The "model 2" neglects this interface and basin and the material property of basin region in "model 1" is the same as sedimentary layer. The epicentral distance of center of the structure cluster $\mathrm{S} 1$, which is also the center of basin in "model 1", is 5.18 $\mathrm{km}$. The b1-b4 and b6-b10 are identical 3-bay 12-story plane frames. The b5 and b6 are identical 3bay 6-story frames.

For the earth media, two different geological configuration models are constructed to obtain earthquake responses of structure cluster on the surface of earth media. The models are referred to hereafter as "model 1" and "model 2". In "model 1", as is shown in Figure 2, the geological structure includes basin, sedimentary layer and half-space bedrock. The length and the maximum depth under free surface of basin is $3.1 \mathrm{~km}$ and $450 \mathrm{~m}$, respectively. The epicentral distance of the center of basin is about $5.18 \mathrm{~km}$. Depth of the uniform interface between sedimentary layer and the half-space bedrock is $1.0 \mathrm{~km}$. In "model 2", comparing to "model 1", the interface between basin and sedimentary layer is neglected and "model 2" is only composed of sedimentary layer with flat free surface and the half-space bedrock. The interface of them is also $1.0 \mathrm{~km}$ in depth. For the "model 1", the material properties are shown in Table 1. For the "model 2", the material properties of only II (sedimentary layer) and III (half-space bedrock) in Table 1 are used.

Table 1. Material properties of the "model 1"

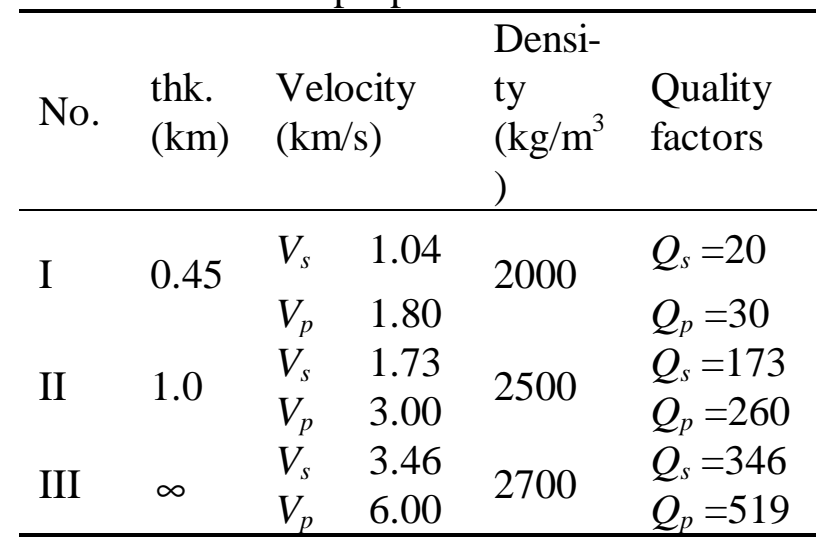

For the frame structure cluster, as is shown in Figure 2, I consider one structure cluster S1, the center of which is $5.18 \mathrm{~km}$ far from the epicenter. Cluster S1 consists of $8 \mathrm{RC}$ plane frame structures of 3-bay 12-storey (see b1-b4 and b6-b10 in Figure 2) and 2 RC plane frame structures (see b5 and b6 in Figure 2) of 3-bay 6-storey distributed with equal interval of $27.6 \mathrm{~m}$. The spans of all plane frame structures are $6.9 \mathrm{~m}$. C25 concrete is used in all structural members. Elastic modulus and density of concrete are respective $2.8 \times 10^{10} \mathrm{~N} / \mathrm{m}^{2}$ and $2500 \mathrm{~kg} / \mathrm{m}^{3}$. 


\section{Simulation results}

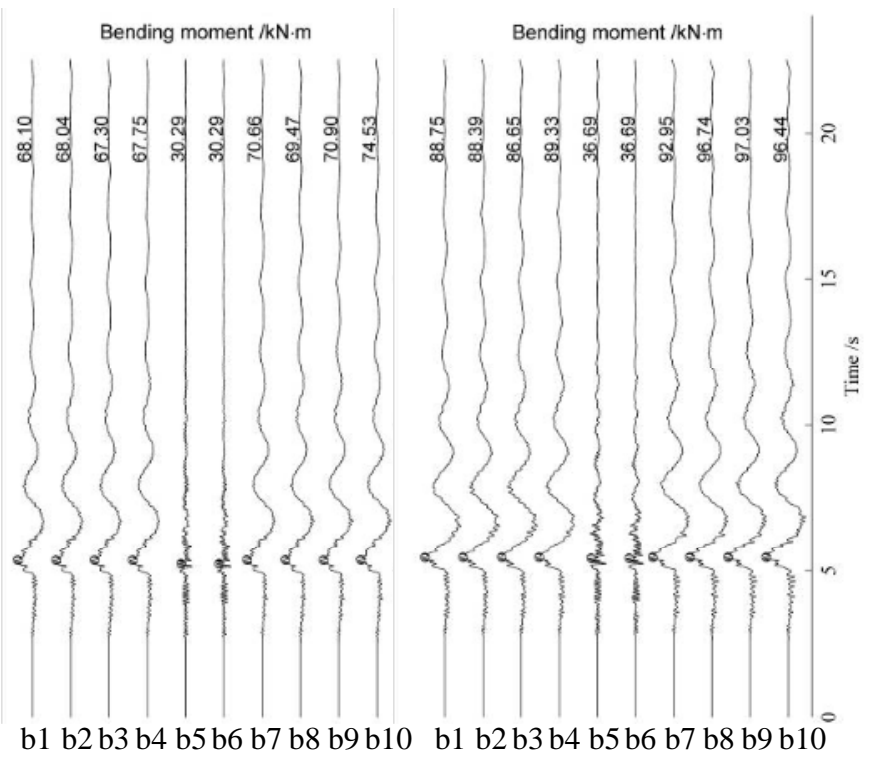

(a)

(b

Figure 3. The bending moments of structure cluster (a) without basin and (b) with basin during a hypothetical $M_{\mathrm{w}} 6.0$ earthquake. The outputs is the left beam end of the first bay in the sixth story of the structures b1-b10. The symbol circle denotes the position of peak bending moment of the output for each structure.

Figure 3 shows time history curves of the bending moments of structure cluster without basin and with basin during a hypothetical $M_{\mathrm{w}} 6.0$ near-fault earthquake. The outputs is the left beam end of the first bay in the sixth story of the structures b1-b10. Compared with the case without basin, the increase rate of peak values of the bending moments is about $21.1 \%$ (b5 and b6) 39.3\% (b8) for the case with basin. It is shown that the presence of basin can increase greatly the bending moments of plane frame structures in structure cluster at the surface of the basin.

Figure 4 shows snapshots of simulated displacement of all structures in cluster $\mathrm{S} 1$ at time $5.4 \mathrm{~s}$ after initial rupture of the causative fault for the cases without basin and with basin. The simulated displacements includes displacements of ground motion and displacements resulting from structure deformation. Following the figure, the vertical displacement of each structure are apparently larger than the horizontal displacement. Comparing to the case without basin, the horizontal displacement of each 3-bay 12-story structure is larger for the case with basin. In addition, it is observed that the structures b4 and b5 have the trend of beating for both cases without basin and with basin.

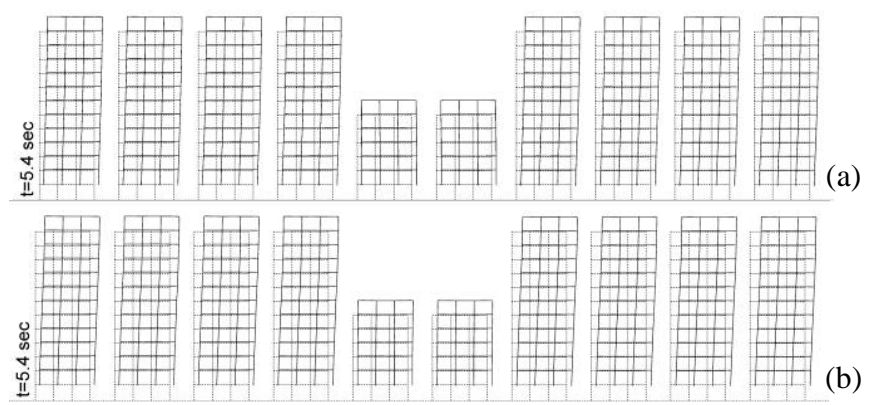

Figure 4. Snapshots of displacements of all structures in structure cluster S1 at time $5.4 \mathrm{~s}$ after initial rupture of the causative fault for the cases (a) without basin and (b) with basin. The deformations of the structures are magnified here by a factor 50 . 
In order to illustrate influence of basin on motion of the structures, the displacement orbits of points on the roof in structures b1 (12-story) and b5 (6-story) without basin and with basin during a $M_{\mathrm{w}} 6.0$ earthquake are shown in Figure 5. For the points on the roof of structure b1 without basin and with basin, the horizontal displacements range from $-2.5 \mathrm{~cm}$ to $6.6 \mathrm{~cm}$ and from $-3.5 \mathrm{~cm}$ to 7.5 $\mathrm{cm}$ (see Figure 5), respectively. Comparing to structure b1 without basin, the increase rate of variation range of structure b1 with basin is $20.9 \%$. For the points on the roof of structure b5 without basin and with basin, the horizontal displacements range from $-0.9 \mathrm{~cm}$ to $5.7 \mathrm{~cm}$ and from $-2.0 \mathrm{~cm}$ to $6.6 \mathrm{~cm}$ (see Figure 5(b)), respectively. Comparing to structure b5 without basin, the increase rate of variation range of structure $\mathrm{b} 5$ with basin is $30.3 \%$. For vertical displacements of points on the roof of both structures, the effect of basin on their variation range, which ranges from $0.0 \mathrm{~cm}$ to about $10.5 \mathrm{~cm}$, is not obvious. Whether the case with basin or not, the orbits of the structures b1 and b5 are in anticlockwise motion during the thrust fault earthquake and the final horizontal and vertical displacements of both structures are about $1.5 \mathrm{~cm}$ and $1.8 \mathrm{~cm}$, respectively. The results show that the presence of basin have a great influence on variation range of horizontal displacement, and have no significant effect on variation range of vertical displacement, direction of overall motion and final displacements of the structures in cluster.

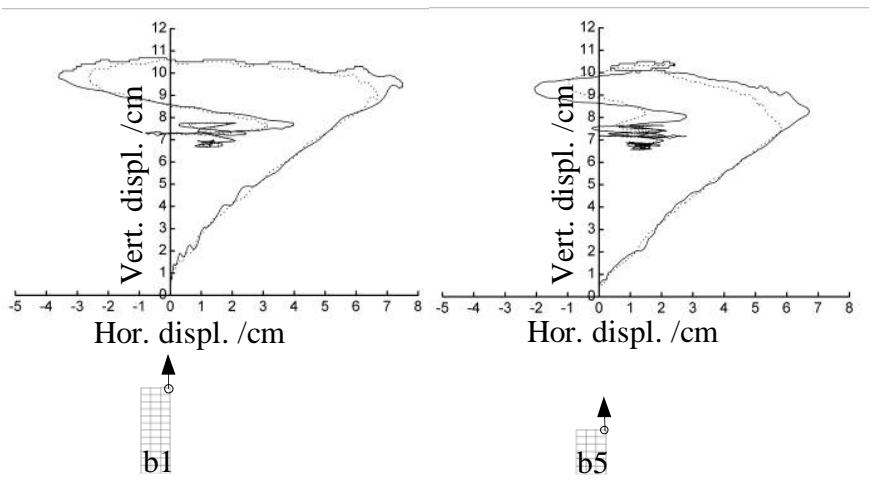

Figure 5. Displacement orbits of points on the roof in structures b1 and b5 without basin (dot line) and with basin (solid line) during a $M_{\mathrm{w}} 6.0$ earthquake.

\section{CONCLUSIONS}

An integrated numerical simulation method, based on the concept of investigated lump, is used to study the influence of basin on earthquake responses of near-fault structure cluster due to the rupture of thrust fault. By constructing two different models of earth media, the seismic responses of nearfault structure cluster on the hanging wall are obtained during a hypothetical $M_{\mathrm{w}} 6.0$ earthquake induced by the rupture of thrust fault. And then the bending moments of structure cluster, snapshots of displacement of all structures and the displacement orbits of points on the roof in structures b1 and b5 are given for the cases without basin and with basin. Some numerical simulation results and conclusions are obtained as follows:

(1) The presence of basin can increase greatly the bending moments of structure cluster at the surface of the basin.

(2) The trend of beating for both cases without basin and with basin is observed from snapshots of simulated displacement of structure cluster.

(3) The presence of basin have a great influence on variation range of horizontal displacement.

(4) The presence of basin have no significant effect on variation range of vertical displacement, direction of overall motion and final displacements of the structures in cluster.

In view of the results and conclusions mentioned above, the geological structure of basin need to be known and should not be neglected when simulating seismic responses of near-fault structure cluster induced by the rupture of causative fault. 


\section{ACKNOWLEDGMENTS}

Project is Supported by Scientific and Technological Research Program of Chongqing Municipal Education Commission (Grant No. KJ1503001).

\section{REFERENCES}

Boutin, C. \& Roussillon, P. 2004. Assessment of the urbanization effect on seismic response. Bulletin of the Seismological Society of America 94(1): 251-268.

Boutin, C. \& Roussillon, P. 2006. Wave propagation in presence of oscillators on the free surface. International Journal of Engineering Science 44: 180-204.

Day, S.M. Graves, R.W. Bielak, J. Dreger, D. Larsen, S. Olsen, K.B. Pitark, A. Ramirez-Guzman, L. 2008. Model for basin effects on long-period response spectra in Southern California. Earthquake Spectra 24(1): 257-277.

Graves, R.W. Pitarka, A. \& Somerville P.G. 1998. Ground-motion amplification in the Santa Monica area: effects of shallow basin-edge structure. Bulletin of the Seismological Society of America 88(5): 1224-1242.

Graves, R.W. 2008. The seismic response of the San Bernardino basin region during the 2001 Big Bear Lake earthquake. Bulletin of the Seismological Society of America 98: 241-252.

Graves, R.W. \& Wald, D.J. 2004. Observed and simulated ground motions in the San Bernardino basin region for the Hector Mine, California, earthquake. Bulletin of the Seismological Society of America 94: 131-146.

Groby, J.P. Tsogka, C. \& Wirgin, A. 2005. Simulation of seismic response in a city-like environment. Soil Dynamics and Earthquake Engineering 25(7-10): 487-504.

Groby, J.P. \& Wirgin, A. 2008. Seismic motion in urban sites consisting of blocks in welded contact with a soft layer overlying a hard half-space. Geophysical Journal International 172(2): 725758.

Guéguen, P. Bard, P.Y. Semblat, J.F. 2000. Engineering seismology: seismic hazard and risk analysis: seismic hazard analysis from soil-structure to site-city interaction. 12th World Conference on Earthquake Eng., Auckland, New Zealand, 2000, International Association for Earthquake Engineering, Paper 0555.

Guéguen, P. Bard, P.Y. Chávez-García, F. 2002. Site-city seismic interaction in Mexico city-like environments: an analytical study. Bulletin of the Seismological Society of America 92(2): 794811.

Guidotti, R. Mazzieri, I. Stupazzini, M. Dagna P. 2012. 3D numerical simulation of the site-city Interaction during the 22 February $2011 \mathrm{M}_{\mathrm{W}} 6.2$ Christchurch earthquake. Electronic proceedings of the 15th World Conference of Earthquake Engineering, 15th WCEE, 24-28. Portugal: Lisbon.

Isbiliroglu, Y. Taborda, R. \& Bielak, J. 2015. Coupled soil-structure interaction effects of building clusters during earthquakes. Earthquake Spectra 31(1): 463-500.

Kham, M. Semblat, JF. Bard, PY. \& Dangla, P. 2006. Seismic site-city interaction: main governing phenomena through simplified numerical models. Bulletin of the Seismological Society of America 96(5): 1934-1951.

Liu, T. Luan, Y. Zhong, W. 2012. Earthquake responses of clusters of building structures caused by a near-field thrust fault. Soil Dynamics and Earthquake Engineering 42: 56-70.

Liu, T. \& Zhong, W. 2014. Earthquake responses of near-fault frame structure clusters due to thrust fault by using flexural wave method and viscoelastic model of earth medium. Soil Dynamics and Earthquake Engineering 61-62: 57-62.

Lombaert, G. \& Clouteau, D. 2006. Resonant multiple wave scattering in the seismic response of a city. Waves in Random and Complex Media 16: 205-230.

Lombaert, G. \& Clouteau, D. 2009. Elastodynamic wave scattering by finite-sized resonant scatterers at the surface of a horizontally layered halfspace Journal of the Acoustic Society of America 125: 2041-2052. 
Morales, J., Singh, S.K. \& Ordaz, M. 1996. Analysis of the Granada (Spain) earthquake of 24 June, $1984(\mathrm{M}=5)$ with emphasis on seismic hazard in the Granada basin. Tectonophysics 257: 253263.

Pitarka, A. \& Irikura K. 1996. Basin structure effects on long-period strong motions in the San Fernando valley and the Los Angeles basin from the 1994 Northridge earthquake and an aftershock. Bulletin of the Seismological Society of America 86(1B): S126-S137.

Semblat, J.F. Kham, M. Guéguen, P. Bard, P.Y. \& Duval, A.M. 2002. Site-city interaction through modifications of site effects. on 7th U.S. Conference on Earthquake Engineering. Boston.

Semblat, J.F. Kham, M. Bard, P.Y. \& Guéguen, P. 2004. Could "site-city interaction" modify site effects in urban areas? in Proceedings of the 13th World Conference on Earthquake Engineering, Canadian Association for Earthquake Engineering, Ed., Vancouver, British Columbia, Canada, August 2004. International Association for Earthquake Engineering, Paper 1978.

Semblat, J.F. Kham, M. Bard, P.Y. 2008. Seismic-wave propagation in alluvial basins and influence of site-city interaction. Bulletin of the Seismological Society of America 98(6): 2665-2678.

Tsogka, C. \& Wirgin, A. 2003a. Simulation of seismic response in an idealized city. Soil Dynamics and Earthquake Engineering 23: 391-402.

Tsogka, C. \& Wirgin, A. 2003b. Seismic response of a set of blocks partially imbedded in soft soil. Comptes Rendus Mecanique 331(3): 217-224.

Uenishi, K. 2010. The Town Effect: Dynamic Interaction between a Group of Structures and Waves in the Ground. Rock Mechanics and Rock Engineering 43(6): 811-819.

Uenishi, K. 2013. "Unexpected" failure patterns and dynamic collective behaviour of an assembly of buildings subjected to horizontal impact. Engineering Failure Analysis 35: 125-132.

Wirgin, A. \& Bard P.Y. 1996. Effects of buildings on the duration and amplitude of ground motion in Mexico city. Bulletin of the Seismological Society of America 86(3): 914-920.

Zhong, W. \& Liu, T. 2016. Application of an investigated lump method to the simulation of ground motion for Beichuan town during the Wenchuan earthquake. Journal of Earthquake and Tsunami 10(1): 1650002-1-1650002-14. 